\title{
Prevalence and genetic characterisation of HTLV-1 and 2 dual infections in patients with pulmonary tuberculosis in Central-West Brazil
}

\author{
Aline Garcia Kozlowski', Megmar Aparecida dos Santos Carneiro', \\ Márcia Alves Dias de Matos', Sheila Araújo Teles², João Alves Araújo Filho',3, \\ Koko Otsuki ${ }^{4}$, Ana Carolina Paulo Vicente ${ }^{4}$, Regina Maria Bringel Martins ${ }^{1 /+}$
}

${ }^{1}$ Instituto de Patologia Tropical e Saúde Pública ${ }^{2}$ Faculdade de Enfermagem, Universidade Federal de Goiás, Goiânia, GO, Brasil

${ }^{3}$ Hospital de Doenças Tropicais Anuar Auad, Goiânia, GO, Brasil ${ }^{4}$ Instituto Oswaldo Cruz-Fiocruz, Rio de Janeiro, RJ, Brasil

Human T-cell lymphotropic virus (HTLV) may impact the clinical course of tuberculosis (TB). Both infections are highly endemic in Brazil. The aim of this study was to assess the prevalence of HTLV-1/2 in TB patients in CentralWest Brazil and to perform a genetic characterisation of the respective isolates. Of the 402 patients, six (1.49\%) were positive for anti-HTLV and five (1.24\%; 95\% confidence interval: 0.46-3.05) were infected with HTLV-1/2. Genetic characterisation demonstrated that the four HTLV-1 isolates belonged to the Transcontinental subgroup A of the Cosmopolitan subtype $a$ and that the HTLV-2 isolate belonged to subtype a $(H T L V-2 a / c)$. The prevalence of HTLV infection observed in this study is higher than that observed in local blood donors and the HTLV-1 and 2 subtypes identified are consistent with those circulating in Brazil.

Key words: HTLV-1 - HTLV-2 - tuberculosis - prevalence

Human T-cell lymphotropic virus type 1 (HTLV-1) is the aetiological agent of a number of major diseases, such as adult T-cell leukaemia/lymphoma, HTLV-1associated myelopathy/tropical spastic paraparesis and other inflammatory diseases. In addition, HTLV-1 infection alters the immune response, thereby increasing the risk of acquiring other infectious such as tuberculosis (TB) and strongyloidiasis (Gonçalves et al. 2010). This virus is endemic to southwestern Japan, Melanesia, sub-Saharan Africa, the Caribbean islands and some regions of South America (Gessain \& Cassar 2012). Based on analyses of the HTLV-1 long terminal repeat (LTR) region, seven genetic subtypes have been defined (a-g). The 1a, or Cosmopolitan subtype, is the most widespread (Gonçalves et al. 2010, Gessain \& Cassar 2012).

Although HTLV-2 disease outcomes remain poorly defined, HTLV-2 has been associated with neurological disorders and an increased incidence of respiratory infections. This virus is prevalent in native Amerindian populations and is relatively frequent among intravenous drug users in Europe and North America. Three genetic subtypes ( $a, b$ and d) of HTLV-2 have been reported based on the nucleotide diversity of their respective LTR regions (Roucoux \& Murphy 2004).

HTLV-1 is associated with increased susceptibility to Mycobacterium tuberculosis infection and more severe TB (Pedral-Sampaio et al. 1997, Marinho et al. 2005, Bastos et al. 2009, 2012). Because HTLV-1 and

doi: 10.1590/0074-0276130230

Financial support: FAPEG

+ Corresponding author: rbringel.iptsp.ufg@gmail.com

Received 29 April 2013

Accepted 12 August 2013
TB may co-exist in patients from endemic areas, coinfection may also influence TB transmission and the epidemiology of the disease (Bastos et al. 2009). Although HTLV-1 may impact patients with TB, there is little information on the prevalence of HTLV among TB patients in Brazil, one of 22 countries that comprise $82 \%$ of all TB cases worldwide (MS 2012). A few studies conducted in the Northeast Region of Brazil have reported high prevalence rates of HTLV-1 among TB patients in the city of Salvador, state of Bahia (Moreira et al. 1993, Pedral-Sampaio et al. 1997, Marinho et al. 2005, Bastos et al. 2009). However, there is a lack of data on HTLV prevalence among TB patients in other Brazilian regions and HTLV isolates have not been characterised in these patients. Therefore, the aim of the present study was to assess the prevalence of HTLV-1/2 in patients with TB in Central-West Brazil and to genetically characterise their respective isolates.

A cross-sectional study was conducted from April 2008-March 2010 at the Anuar Auad Hospital, the reference hospital for infectious diseases in the city of Goiânia, the capital of the state Goiás, Central-West Brazil. During the present study, this hospital was the main centre for the treatment of TB patients in Goiânia (nearly $70 \%$ of TB patients in this city). All patients with a clinical diagnosis of TB who were under treatment at outpatient or inpatient units at the hospital were invited to participate in this study.

TB patients were recruited by physicians, who explained the study objectives and procedures. Written informed consent was obtained from all participants prior to the start of the study. Patients were interviewed to obtain demographic characteristics and identify risk factors associated with HTLV transmission. The protocol used for the present study was approved by the Ethical Committee of the Anuar Auad Tropical Disease Hospital. 
Blood was collected $(10 \mathrm{~mL})$ from all participants and serum samples were evaluated by ELISA for the presence of HTLV antibodies (anti-HTLV, Murex HTLVI+II) (Murex Biotech, Dartford, UK). Patients who tested positive for HTLV were also tested for co-infection with human immunodeficiency virus (HIV) (anti-HIV-1.2.0) (Murex Biotech), hepatitis B virus (HBV) (presence of hepatitis B surface antigen, HBsAg, Hepanostika HBsAg Ultra) (BioMérieux, Boxtel, The Netherlands) and hepatitis C virus (HCV) (anti-HCV, Hepanostika Ultra) (Biomedical, Shanghai, China) by ELISA. HIV-positive samples were confirmed by western blot analysis (Bio Rad Laboratories, Marnes La Coquette, France).

DNA was extracted from whole blood samples of HTLV seropositive subjects using the QIAamp DNA Blood Mini kit (Qiagen, Hilden, Germany) according to the manufacturer's instructions. Polymerase chain reactions (PCR) targeting the HTLV-1 LTR and tax and orf-I genes (Liu et al. 1994, Furukawa et al. 2000, Iñiguez et al. 2005) and the HTLV-2 LTR and tax gene (Eiraku et al. 1996) were performed. PCR products were purified using the QIAamp PCR purification kit (Qiagen) and both strands were directly sequenced with an internal primer set using the Big Dye Terminator v.3.1 Cycle Sequencing Ready Reaction Kit (Applied Biosystems, Foster City, CA, USA) in a 3100 Automated DNA Sequencer (Applied Biosystems).

The HTLV LTR sequences were edited and aligned using BioEdit v5.0.9. (Department of Microbiology, North Carolina State University, NC, USA) and CLUSTALW, respectively. A neighbour-joining (NJ) tree was constructed using PAUP* software version 4.0. The Hasegawa, Kishino \& Yano model with gamma distribution was selected using the Modeltest 3.7 software. The NJ tree was evaluated by bootstrap analysis of 1,000 replicates. Novel nucleotide sequences identified in the present study were deposited in GenBank under the accessions JX184913-JX184924.

Of 425 patients who were invited to take part in the study, 402 (94.6\%) agreed to participate. The study population ranged in age from three-86 years (average 44.1 years). Most patients were males (71.9\%) and non-white (65.9\%). Among adults ( $\geq 15$ years old), $42 \%$ were single, $63.5 \%$ reported a familial income of US $\$ 300$ and $79.8 \%$ had received nine years or less of formal education.

Among the 402 TB patients, six (1.49\%) were found to be HTLV-1/2 positive by ELISA. Of these, infection was confirmed in five following the detection of the tax gene, resulting in an overall HTLV-1/2 prevalence of $1.24 \%$ [95\% confidence interval (CI): 0.46-3.05]. This prevalence was higher than that observed in local blood donors $(0.13 \%$; 95\% CI: 0.11-0.17) (AG Kozlowski, unpublished observations).

Relative to other data reported in TB patients in Brazil, the prevalence found in this study was within the CI range reported in the city of Fortaleza, state of Ceará $(0.66 \%$; 95\% CI: 0.17-2.10) in the Northeast Region of Brazil (Broutet et al. 1996), but lower than that observed in Salvador (4.27-10.83\%) (Moreira et al. 1993, Pedral-Sampaio et al. 1997, Marinho et al. 2005, Bastos et al. 2009), where a population-based study demonstrated a high HTLV-1 infection prevalence (1.76\%) (Dourado et al. 2003).

Four $(0.99 \%)$ TB patients were infected with HTLV-1 and one $(0.25 \%)$ patient was infected with HTLV-2. As shown in the Table, the HTLV-1-infected individuals ranged in age from 28-74 years old. Three were males and one was female. All reported unprotected sex with multiple partners (USMP). Of these patients, two reported a history of sexually transmitted infections (STIs) and both were co-infected with HBV. One of these patients was also infected with HIV. No participants reported receiving a blood transfusion. These data are consistent with previously reported findings that sexual transmission is the primary route of HTLV-1 transmission (Gonçalves et al. 2010).

The phylogenetic analysis of the HTLV-1 LTR region from three TB patients (TB-83, TB-305 and TB-401) showed that the virus belonged to the Cosmopolitan subtype HTLV-1a Transcontinental subgroup A (A in Figure). In addition, a fourth isolate (TB-152) was also classified as subtype HTLV-1a Transcontinental subgroup A following nucleotide sequence analysis of the orf-I gene

TABLE

Demographic data, risk factors, co-infections and

human T-cell lymphotropic virus (HTLV) types/subtypes among tuberculosis (TB) patients in Central Brazil

\begin{tabular}{|c|c|c|c|c|c|c|}
\hline \multirow[b]{2}{*}{ Patient } & \multirow[b]{2}{*}{ Gender } & \multirow{2}{*}{$\begin{array}{c}\text { Age } \\
\text { (years) }\end{array}$} & \multirow[b]{2}{*}{ Risk factors } & \multirow[b]{2}{*}{ Co-infections } & \multicolumn{2}{|c|}{$\begin{array}{c}\text { HTLV } \\
\text { types/subtypes }\end{array}$} \\
\hline & & & & & HTLV-1 & HTLV-2 \\
\hline TB-83 & Male & 74 & USMP, STI & $\mathrm{HBV}$ & $\mathrm{aA}$ & - \\
\hline TB-152 & Male & 50 & USMP & - & $\mathrm{aA}$ & - \\
\hline TB-305 & Female & 28 & USMP & - & $\mathrm{aA}$ & - \\
\hline TB-401 & Male & 56 & USMP, STI & HBV, HIV & $\mathrm{aA}$ & - \\
\hline TB-100 & Male & 45 & IDU, USMP, STI, I & HBV, HCV, HIV & - & $\mathrm{a} / \mathrm{c}$ \\
\hline
\end{tabular}

HBV: hepatitis B virus; HCV: hepatitis C virus; HIV: human immunodeficiency virus; I: incarceration; IDU: intravenous drug use; STI: sexually transmitted infections; USMP: unprotected sex with multiple partners. 
(data not shown). This HTLV-1 subtype is endemic to all Brazilian regions (Martins et al. 2010, Rego et al. 2010, de Oliveira et al. 2012, Magri et al. 2012).

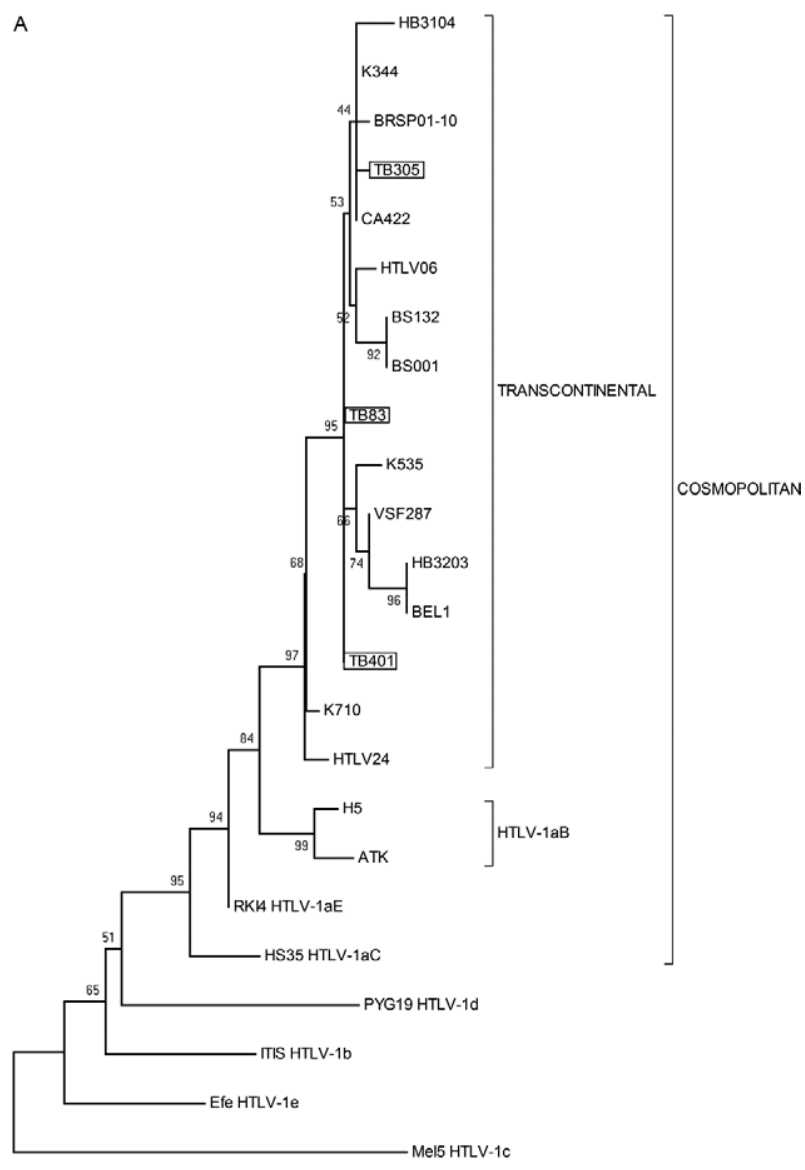

0.01

B

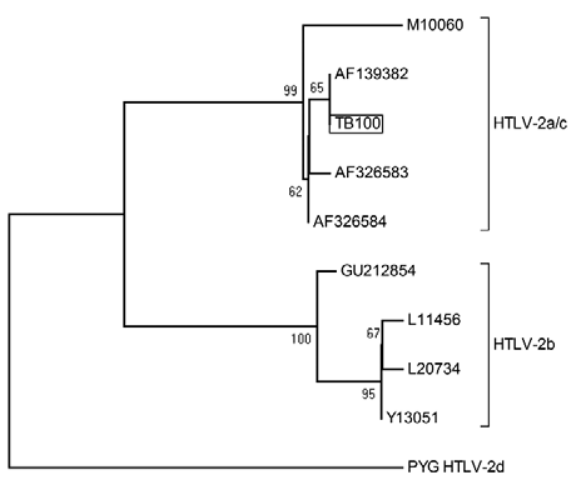

$\longrightarrow .005$

Phylogenetic trees of human T-cell lymphotropic virus type 1 (HTLV-1) and HTLV-2 isolates. A: based on HTLV-1 long terminal repeat (LTR) region, including three sequences from patients with tuberculosis (TB) in Central Brazil and GenBank sequences of subtypes a-d; B: on HTLV-2 LTR region, including one sequence from TB patient and GenBank sequences of subtypes a, b and d. The phylogenetic trees were constructed using the neighbour-joining method based on Hasegawa, Kishino \& Yano model and $\gamma$-distribution. The number on the trees represents bootstrap values.
The phylogenetic analysis of the HTLV-2 LTR region (B in Figure) revealed that the HTLV-2 isolate (TB-100) belonged to subtype a (HTLV-2a/c). This is also the most prevalent of the endemic HTLV-2 subtypes in Brazil (Ishak et al. 1995, Alcantara et al. 2003, Novoa et al. 2007, Magri et al. 2010, de Oliveira et al. 2012) and corresponds to one cluster within subtype 2a; this cluster was previously called HTLV-2c (Eiraku et al. 1996). It is hypothesised that the presence of HTLV-2 in urban populations is related to intravenous drug use (Alcantara et al. 2003, Novoa et al. 2007, Magri et al. 2010), which could explain the presence of this virus subtype in the studied population. In fact, the HTLV-2-infected individual (45 year old male) reported intravenous drug use. Co-infections with HIV, HBV and HCV were also detected in this patient (Table). The risk of these infections is likely linked to common modes of transmission, including parenteral exposure related to the sharing of syringes/needles and other drug-related paraphernalia, which could lead to blood-to-blood contact and risky sexual behaviours, such as USMP and STIs. In addition, secondary risk factors, such as a history of incarceration, should also be considered.

HTLV may have an important impact on the clinical course of TB. One retrospective study reported that HTLV-1 increased the mortality rate of TB (PedralSampaio et al. 1997). Bastos et al. (2009) observed that patients with HTLV-1 infection and TB were more likely to have been previously treated and hospitalised for TB. Although the design of this study did not permit us to observe the impact of HTLV on the clinical course of TB, two HTLV-1/TB co-infected patients (TB-83 and TB-152) had received previous treatment for TB and one (TB-305) was hospitalised due to TB. Therefore, further clinical prospective studies with close follow-up of HTLV/TB coinfected patients are necessary to better understand the influence of HTLV infection on the course of TB.

In conclusion, the prevalence of HTLV-1/2 infections among TB patients in Central-West Brazil was higher than that observed in local blood donors. The HTLV-1 and 2 subtypes identified in the studied population are consistent with those circulating in Brazil.

\section{ACKNOWLEDGEMENTS}

To Nádia Rúbia Silva Reis and Rodrigo Sebba Aires, for their collaboration during the data and blood collection, and to the doctors, nurses, laboratory staff and other staff of the Anuar Auad Tropical Disease Hospital, for assistance with sample and data collection and collaboration.

\section{REFERENCES}

Alcantara LC, Shindo N, van Dooren S, Salemi M, Costa MC, Kashima S, Covas DT, Vandamme AM, Galvão-Castro B 2003. Brazilian HTLV type 2a strains from intravenous drug users (IDUs) appear to have originated from two sources: Brazilian Amerindians and European/North American IDUs. AIDS Res Hum Retroviruses 19: 519-523.

Bastos ML, Osterbauer B, Mesquita DL, Carrera CA, Albuquerque MJ, Silva L, Pereira DN, Riley L, Carvalho EM 2009. Prevalence of human T-cell lymphotropic virus type 1 infection in hospitalized patients with tuberculosis. Int J Tuberc Lung Dis 13: 1519-1523.

Bastos ML, Santos SB, Souza A, Finkmoore B, Bispo O, Barreto T, Cardoso I, Bispo I, Bastos F, Pereira D, Riley L, Carvalho EM 
2012. Influence of HTLV-1 on the clinical, microbiologic and immunologic presentation of tuberculosis. BMC Infect Dis 12: 199.

Broutet N, Sousa AQ, Basilio FP, Sa HL, Simon F, Dabis F 1996. Prevalence of HIV-1, HIV-2 and HTLV antibody, in Fortaleza, Ceará, Brazil, 1993-1994. Int J STD AIDS 7: 365-369.

de Oliveira EH, Oliveira-Filho AB, Souza LA, da Silva LV, Ishak MO, Ishak R, Vallinoto AC 2012. Human T-cell lymphotropic virus in patients infected with HIV-1: molecular epidemiology and risk factors for transmission in Piauí, northeastern Brazil. Curr HIV Res 10: 700-707.

Dourado I, Alcântara LC, Barreto ML, Teixeira MG, Galvão-Castro B 2003. HTLV-I in the general population of Salvador, Brazil: a city with African ethnic and sociodemographic characteristics. J Acquir Immune Defic Syndr 34: 527-531.

Eiraku N, Novoa P, Ferreira MC, Monken C, Ishak R, Ferreira OC, Zhu SW, Lorenço R, Ishak M, Azvedo V, Guerreiro J, de Oliveira MP, Loureiro P, Hammerschlak N, Ijichi S, Hall WM 1996. Identification and characterization of a new and distinct molecular subtype of human T-cell lymphotropic virus type 2. J Virol 70: 1481-1492.

Furukawa Y, Yamashita M, Usuku K, Izumo S, Nakagawa M, Osame M 2000. Phylogenetic subgroups of human T cell lymphotropic virus (HTLV) type I in the tax gene and their association with different risks for HTLV-I-associated myelopathy/tropical spastic paraparesis. J Infect Dis 182: 1343-1349.

Gessain A, Cassar O 2012. Epidemiological aspects and world distribution of HTLV-1 infection. Front Microbiol 3: 388.

Gonçalves DU, Proietti FA, Ribas JG, Araújo MG, Pinheiro SR, Guedes AC, Carneiro-Proietti AB 2010. Epidemiology, treatment and prevention of human T-cell leukemia virus type 1-associated diseases. Clin Microbiol Rev 23: 577-589.

Iñiguez AM, Otsuki K, Magalhães GP, Silva EA, Vicente AC 2005. Genetic markers on the HTLV-1 p12I protein sequences from Brazilian HAM/TSP patients and asymptomatic HTLV-1 carrier isolates. AIDS Res Hum Retroviruses 21: 580-582.

Ishak R, Harrington Jr WJ, Azevedo VN, Eiraku N, Ishak MO, Guerreiro JF, Santos SB, Kubo T, Monken C, Alexander S 1995. Identification of human $\mathrm{T}$ cell lymphotropic virus type IIa infection in the Kayapo, an indigenous population of Brazil. AIDS Res Hum Retroviruses 11: 813-821.

Liu HF, Vandamme AM, Kazadi K, Carton H, Desmyter J, Goubau P 1994. Familial transmission and minimal sequence variability of human T-lymphotropic virus type I (HTLV-I) in Zaire. AIDS Res Hum Retroviruses 10: 1135-1142.

Magri MC, Brigido LF, Rodrigues R, Morimoto HK, Ferreira JL, Caterino-de-Araujo A 2012. Phylogenetic and similarity analysis of HTLV-1 isolates from HIV-coinfected patients from the South and Southeast regions of Brazil. AIDS Res Hum Retroviruses 28: 110-114.

Magri MC, Morimoto HK, Brigido LFM, Rodrigues R, Caterinode-Araujo A 2010. Long terminal repeat sequence analysis of HTLV-2 molecular variants identified in southern Brazil. AIDS Res Hum Retroviruses 26: 1327-1331.

Marinho J, Galvão-Castro B, Rodrigues LC, Barreto ML 2005. Increased risk of tuberculosis with human T-lymphotropic virus-1 infection: a case-control study. J Acquir Immune Defic Syndr 40: 625-628.

Martins RM, do Nascimento LB, Carneiro MA, Teles SA, Lopes CL, Motta-Castro AR, Otsuki K, Vicente AC 2010. HTLV-1 intrafamilial transmission through three generations in an isolated Afro-Brazilian community. J Clin Virol 48: 155-157.

Moreira Jr ED, Ribeiro TT, Swanson P, Sampaio Filho C, Melo A, Brites C, Badaro R, Toedter G, Lee H, Harrington Jr W 1993. Seroepidemiology of human T-cell lymphotropic virus type I/II in northeastern Brazil. J Acquir Immune Defic Syndr 6: 959-963.

MS - Ministério da Saúde 2012. Tuberculose no Brasil. Available from: portalsaude.saude.gov.br/portalsaude/index.cfm?portal=pagina. visualizarTexto $\&$ codConteudo $=6406 \& \operatorname{codModuloArea}=783 \& \mathrm{c}$ hamada=boletim-1/2012 tuberculose-no-brasil.

Novoa P, de Oliveira ACP, Vergara MPP, Duarte AJS, Casseb J 2007. Molecular characterization of human T-cell lymphotropic virus type 2 (HTLV-II) from people living in urban areas of São Paulo city: evidence of multiple subtypes circulation. $J$ Med Virol 79: 182-187.

Pedral-Sampaio DB, Martins Netto E, Pedrosa C, Brites C, Duarte M, Harrington Jr W 1997. Co-infection of tuberculosis and HIV/ HTLV retroviruses: frequency and prognosis among patients admitted in a Brazilian hospital. Braz J Infect Dis 1: 31-35.

Rego FFA, Mota-Miranda A, Santos ES, Galvão-Castro B, Alcântara LC 2010. Seroprevalence and molecular epidemiology of HTLV-1 isolates from HIV-1 co-infected women in Feira de Santana, Bahia, Brazil. AIDS Res Hum Retroviruses 26: 1333-1339.

Roucoux DF, Murphy EL 2004. The epidemiology and disease outcomes of human T-lymphotropic virus type II. AIDS Rev 6: 144-154. 